\title{
A Zebrafish Heart Failure Model for Assessing Therapeutic Agents
}

\author{
Xiao-Yu Zhu, ${ }^{1,2}$ Si-Qi Wu, ${ }^{1}$ Sheng-Ya Guo, Hua Yang, ${ }^{1}$ Bo Xia, Ping Li,, and Chun-Qi Li
}

\begin{abstract}
Heart failure is a leading cause of death and the development of effective and safe therapeutic agents for heart failure has been proven challenging. In this study, taking advantage of larval zebrafish, we developed a zebrafish heart failure model for drug screening and efficacy assessment. Zebrafish at 2 dpf (days postfertilization) were treated with verapamil at a concentration of $200 \mu \mathrm{M}$ for $30 \mathrm{~min}$, which were determined as optimum conditions for model development. Tested drugs were administered into zebrafish either by direct soaking or circulation microinjection. After treatment, zebrafish were randomly selected and subjected to either visual observation and image acquisition or record videos under a Zebralab Blood Flow System. The therapeutic effects of drugs on zebrafish heart failure were quantified by calculating the efficiency of heart dilatation, venous congestion, cardiac output, and blood flow dynamics. All 8 human heart failure therapeutic drugs (LCZ696, digoxin, irbesartan, metoprolol, qiliqiangxin capsule, enalapril, shenmai injection, and hydrochlorothiazide) showed significant preventive and therapeutic effects on zebrafish heart failure $(p<0.05, p<0.01$, and $p<0.001)$ in the zebrafish model. The larval zebrafish heart failure model developed and validated in this study could be used for in vivo heart failure studies and for rapid screening and efficacy assessment of preventive and therapeutic drugs.
\end{abstract}

Keywords: zebrafish, heart failure, verapamil, cardiovascular diseases

\section{Introduction}

$\mathbf{H}$ EART FAILURE IS CHARACTERIZED BY gradual deterioration of cardiac function, culminating in erratic heart rhythm and edema and eventually death. ${ }^{1}$ Approximately $50 \%$ of the patients diagnosed with heart failure could die within 5 years. Most heart failures are chronic processes and commonly result from long-term hypertension or cardiovascular diseases. ${ }^{2}$ However, acute heart failure may occur due to sudden worsening of the chronic heart failure condition, infection, or chemotherapeutic treatments., ${ }^{3,4}$ Weakening heart function often causes congestion, or fluid buildup in the lungs and other tissues, by hindering the flow of blood through the chambers of the heart. As a reflex response, several physiological systems, including the neurohormone, antidiuresis, and rennin-angiotensin system, are triggered upon stress to the heart's normal function to compensate for the insufficient cardiac output. ${ }^{2}$

Development of new animal models and rapid assay methods for heart failure research and drug screening is urgently needed. The current in vitro and ex vivo heart failure assays have a limited value due to lack of either heart structures or drug absorption, distribution, metabolism, and excretion, and extrapolation of these results to the whole organism is often challenging. Conventional mammalian in vivo heart failure models are usually laborious, costly, and time-consuming, restricting their applications in early screening. 5

The developing embryonic and larval zebrafish are small and transparent, enabling nonintrusive visualization of organs and biological processes in vivo with a high resolution. Larval zebrafish have recently shown many advantages for human disease studies and drug discovery. ${ }^{6}$ Zebrafish heart is highly comparable with human heart in structures, functions, signal pathways, and ion channels, and both are muscles designed to pump oxygen-carrying blood through the body. ${ }^{7}$ As in all vertebrates, the heart is the first organ to function in zebrafish and it develops rapidly and is fully formed by 2 days postfertilization (dpf). Zebrafish cardiac contraction begins at $22 \mathrm{hpf}$, initially as a peristaltic wave, which then develops into coordinated contractions of the atrium and ventricle by $36 \mathrm{hpf}^{7}$ The characteristics of cardiac myocyte action

\footnotetext{
${ }^{1}$ State Key Laboratory of Natural Medicines, China Pharmaceutical University, Nanjing City, China.

${ }^{2}$ Hunter Biotechnology, Inc., Hangzhou City, China.
} 
potentials from zebrafish closely resemble those of human myocytes, as orthologs of the cardiac ion channels found in humans exist in zebrafish, for example, zERG (ortholog of human hERG). ${ }^{8}$ Interestingly, in zebrafish, zERG blockade induces bradycardia or a decoupling of A-V beat rates leading to a $2: 1$ block, thus allowing detection without an electrocardiogram. ${ }^{9}$ The zebrafish heart has a coronary vasculature with the heart rate $(120-140 \mathrm{bpm})$ similar to those observed in humans, whereas in mice, the heart rate is much higher (300-600 bpm). ${ }^{10}$ The zebrafish electrocardiogram is also similar to humans with a distinct $\mathrm{P}$-wave, $\mathrm{QRS}$ complex, and T-wave, although the QTc interval is slightly shorter probably due to lower culture temperatures. ${ }^{11}$ These studies suggest that zebrafish have similar electrical and mechanical properties to the mammalian heart and appear to respond very similarly to drug treatment as humans. ${ }^{12,13}$

Zebrafish (as a cardiovascular system animal model) have been used for assessing drug toxicity, efficacy, and drug screening. ${ }^{14-17}$ In the present study, we have developed, optimized, and validated a heart failure model in larval zebrafish treated with a heart failure-inducing drug verapamil. The verapamil-treated larval zebrafish developed pericardial edema and venous blood congestion with reduced cardiac output and blood flow velocity, similar to the pathophysiology observed in heart failure patients. This model was further validated with six Federal Drug Administration (FDA)-approved heart failure therapeutic drugs (LCZ696, digoxin, irbesartan, metoprolol, enalapril, and hydrochlorothiazide) and two China FDA (CFDA)approved heart failure therapeutic medicines (qiliqiangxin capsule and shenmai injection). Our results indicate that the zebrafish heart failure model developed and validated in this study is a convenient and predictive animal model for rapid in vivo screening and efficacy assessment of heart failure therapeutic drugs and could potentially speed up heart failure drug discovery and development.

\section{Materials and Methods}

\section{Zebrafish care and maintenance}

Adult $\mathrm{AB}$ strain zebrafish were housed in a light- and temperature-controlled aquaculture facility with a standard 14-h light-10-h dark photoperiod and fed with live brine shrimp twice daily and dry flake once a day. Four to five pairs of zebrafish were set up for natural mating every time. On average, 200-300 embryos were generated. Embryos were maintained at $28^{\circ} \mathrm{C}$ in fish water $(0.2 \%$ Instant Ocean salt in deionized water, $\mathrm{pH}$ 6.9-7.2, conductivity 480-510 mS.cm ${ }^{-1}$, and hardness 53.7-71.6 mg. $\mathrm{L}^{-1} \mathrm{CaCO}_{3}$ ). The embryos were cleaned and staged at 6 and $24 \mathrm{hpf}$ (hours postfertilization). ${ }^{18}$ The zebrafish facility at Hunter Biotechnology, Inc., is accredited by the Association for Assessment and Accreditation of Laboratory Animal Care (AAALAC) International. ${ }^{19}$

\section{Chemicals and drugs}

Verapamil (lot \#: L1303078), qiliqiangxin capsule (lot \#: A1504007), digoxin (lot \#: L1303078), irbesartan (lot \#: 62515050101), metoprolol (lot \#: 43217), and hydrochlorothiazide (lot \#: H150104) were purchased from Aladdin Company (Shanghai, China). LCZ696 was provided by Hansoh Pharma (Shanghai, China). Enalapril (lot \#: CHRKE-AL) was bought from Sigma-Aldrich (St. Louis, USA) and shenmai injection was from Chiatai Qingchunbao (Shanghai, China). Drug stock solutions were prepared in either 100\% dimethyl sulfoxide (DMSO) or $0.9 \%$ sodium chloride, and serial dilutions were made before each experiment. Zebrafish treated with $0.1 \%$ DMSO or $0.9 \%$ sodium chloride served as vehicle controls. Untreated zebrafish were used to confirm that the vehicle solvents did not have an adverse effect on the zebrafish.

\section{Zebrafish heart failure model development}

Cardiac phenotypes can appear as early as the embryonic stage at $48 \mathrm{hpf}$. These changes include distortion of the heart shape and decrease of heart size and gradual decrease of heart rate, ${ }^{20}$ so we chose zebrafish at $48 \mathrm{hpf}$ as an appropriate stage to start verapamil treatment for the heart failure model development. To optimize the verapamil treatment concentration and treatment time period, thirty zebrafish at $2 \mathrm{dpf}$ were distributed into six-well plates (Nest Biotech., Shanghai, China) in $3 \mathrm{~mL}$ of fresh fish water. ${ }^{21,22}$ Zebrafish were treated with 100, 200, and $300 \mu \mathrm{M}$ verapamil for $10 \mathrm{~min}, 30 \mathrm{~min}$, and $1 \mathrm{~h}$, respectively, to induce heart failure. After verapamil treatment, ten zebrafish from each group were randomly selected for visual observation and images were acquired at the diastolic stage of zebrafish heart beating without using an anesthetic under a dissecting stereomicroscope (Olympus, Japan). Quantitative image analysis was performed using image-based morphometric analysis. The resting zebrafish were subjected to video recording under a Zebralab Blood Flow System (Viewpoint, France). Quantitative analysis was performed using video-based analysis. Based on qualitative and quantitative results of area measurements of heart dilatation and venous congestion, cardiac output, and blood flow dynamics reduction, the optimal verapamil treatment concentration and treatment time period were selected.

\section{Determination of no observed adverse effect level}

To determine the no observed adverse effect level (NOAEL) of a testing drug, zebrafish at $2 \mathrm{dpf}$ were treated with a testing drug for $4 \mathrm{~h}$ and mortality and toxicity were recorded at the end of the treatment. In the initial tests, five concentrations $(0.1,1,10,100$, and $500 \mathrm{mg} / \mathrm{L}$ for soaking drugs) or doses $(0.1,1,10,100$, and $500 \mathrm{ng} / \mathrm{zebrafish}$ for microinjected drugs) were used for each drug. If the NOAEL could not be found from initial tests, additional concentrations or doses within the range of $0.01-2000 \mathrm{mg} / \mathrm{L}$ or $0.01-$ $2000 \mathrm{ng} / \mathrm{zebrafish}$ were tested. The NOAEL of a test drug was defined as the maximum concentration or maximum dose that did not induce any observable adverse effect on zebrafish and was determined under a dissecting stereomicroscope by a well-trained zebrafish toxicologist. ${ }^{23}$

\section{Drug delivery by circulation microinjection}

One injectable drug (shenmai injection) was delivered into zebrafish by circulation microinjection as we reported previously. $^{24}$ The drug was dissolved in $0.9 \%$ sodium chloride and diluted to proper concentrations for zebrafish circulation microinjection. Before microinjection, zebrafish were anesthetized with $0.03 \%$ tricaine (Sigma, USA) and loaded on a customized microplate designed specifically for zebrafish 
microinjection. The drug at a designated concentration was loaded into a pulled glass capillary (World Precision Instruments, USA) that was drawn on an electrode puller (NARISHIGE, Japan) and then trimmed to form a needle with a resulting internal diameter of approximately $15 \mu \mathrm{m}$ and outer diameter of approximately $18 \mu \mathrm{m}$. The microneedle was attached to an air-driven Cell Tram (NARISHIGE, Japan). The tip of the needle was inserted into the circulation of zebrafish under a dissecting stereomicroscope and the pulse time was controlled to deliver $10 \mathrm{~nL}$ of the drug solution into the circulation through the glass capillary. Injected zebrafish were transferred to six-well plates, 30 zebrafish per well with $3 \mathrm{~mL}$ of fish water for a treatment period of $24 \mathrm{~h}$. Zebrafish injected with $10 \mathrm{~nL} 0.9 \%$ sodium chloride served as vehicle controls and untreated zebrafish were used to confirm that the vehicle solvent did not have an adverse effect on the zebrafish. ${ }^{24}$

\section{Assessment effects of drugs on zebrafish heart failure}

To assess effects of the tested drugs on heart failure in zebrafish, eight known human heart failure therapeutic drugs (LCZ696, digoxin, irbesartan, metoprolol, qiliqiangxin capsule, enalapril, shenmai injection, and hydrochlorothiazide) were selected for validation of the zebrafish heart failure model. Thirty AB strain zebrafish at $2 \mathrm{dpf}$ were distributed into six-well plates in $3 \mathrm{~mL}$ of fresh fish water. Zebrafish were pretreated with a test drug for $4 \mathrm{~h}$ at serial concentrations or dosages, as indicated in Table 1, followed by treatment with verapamil for another $30 \mathrm{~min}$. Zebrafish treated with $200 \mu \mathrm{M}$ verapamil for $30 \mathrm{~min}$ were used as the heart failure model. Zebrafish treated with $0.1 \%$ DMSO or $0.9 \%$ sodium chloride were used as vehicle controls. Untreated zebrafish were used to confirm that the vehicle solvent did not have an adverse effect on zebrafish. After treatment, zebrafish heart failure was quantified using a method as described above.

\section{Statistical analyses}

One-way ANOVA, followed by Dunnett's test, was used to compare differences among groups. All statistical analyses were performed using the SPSS 16.0 software (SPSS, USA), and $p<0.05$ was considered statistically significant. For quantitative analysis, all data are presented as mean \pm SEM, and results were statistically compared between drug-treated and vehicle-treated zebrafish groups. All experiments were repeated at least three times.

\section{Results}

To develop a zebrafish heart failure model for drug screening and efficacy assessment, the optimal concentration and treatment time period of the heart failure inducer verapamil were first determined. Zebrafish at $2 \mathrm{dpf}$ were treated with verapamil at three concentrations of 100, 200, and $300 \mu \mathrm{M}$ for a variety of time periods from $10 \mathrm{~min}$ to $1 \mathrm{~h}$, heart dilatation and venous congestion reduction were visually confirmed under a dissecting stereomicroscope and further quantified based on image analysis, and the cardiac output and blood flow dynamics were measured and analyzed using a Zebralab Blood Flow System. We found that zebrafish treated with $100 \mu \mathrm{M}$ verapamil for $10 \mathrm{~min}$ to $1 \mathrm{~h}$ did not induce zebrafish heart dilatation and venous congestion at all. Serious cardiovascular toxicity, including pericardial edema, bradycardia, or even no blood circulation, was observed in all zebrafish treated with $300 \mu \mathrm{M}$ verapamil for $10 \mathrm{~min}$ to $1 \mathrm{~h}$.

A time-dependent heart dilatation, venous congestion, cardiac output, and blood flow dynamics reduction were demonstrated in zebrafish treated with $200 \mu \mathrm{M}$ verapamil, of which treatment for $30 \mathrm{~min}$ induced heart failure in $100 \%$ zebrafish, and the heart dilatation, venous congestion, cardiac output, and blood flow dynamics reduction could be markedly rescued when the zebrafish were pretreated with a well-known heart failure therapeutic drug digoxin (Fig. 1). Treatment with $200 \mu \mathrm{M}$ verapamil for $1 \mathrm{~h}$ and $300 \mu \mathrm{M}$ verapamil for $30 \mathrm{~min}$ and $1 \mathrm{~h}$ induced severe heart failure with obvious cardiovascular toxicity, and the heart failure could not be rescued with digoxin pretreatment. In addition, the heartbeat rate was $(183 \pm 5.8) / \mathrm{min}$ in untreated control zebrafish and $(126 \pm 5.3) / \mathrm{min}$ in zebrafish treated with $200 \mu \mathrm{M}$ verapamil for $30 \mathrm{~min}$, indicating that verapamil treatment can result in slower heartbeats, but with no effect on heart rhythm. No observable toxicity or death was found in zebrafish after verapamil treatment. Based on these results, zebrafish treatment with $200 \mu \mathrm{M}$ verapamil for 30 min was selected, as the optimum treatment concentration and treatment period, for subsequent heart failure model development.

To determine whether the zebrafish response to heart failure therapeutics is similar to the response of mammalian model systems, we pretreated the zebrafish with each of the eight known drugs (LCZ696, digoxin, irbesartan, metoprolol, qiliqiangxin capsule, enalapril, shenmai injection, and hydrochlorothiazide) for $4 \mathrm{~h}$, and then incubated them with $200 \mu \mathrm{M}$ verapamil for $30 \mathrm{~min}$. Six to 12 concentrations or dosages of eight known drugs were assessed for each drug (Table 1). The NOAEL was $2.5 \mu \mathrm{g} . \mathrm{mL}^{-1}$ for LCZ696, $10 \mu \mathrm{g} . \mathrm{mL}^{-1}$ for digoxin, $10 \mu \mathrm{g} \cdot \mathrm{mL}^{-1}$ for irbesartan, $10 \mu \mathrm{g} \cdot \mathrm{mL}^{-1}$ for metoprolol, $250 \mu \mathrm{g} \cdot \mathrm{mL}^{-1}$ for qiliqiangxin capsule, $250 \mu \mathrm{g} \cdot \mathrm{mL}^{-1}$ for enalapril, $10 \mathrm{ng}$ for shenmai injection, and $50 \mu \mathrm{g} \cdot \mathrm{mL}^{-1}$ for hydrochlorothiazide, respectively.

As expected, after a 4-h treatment, human heart failure therapeutic drugs, LCZ696, digoxin, irbesartan, metoprolol, qiliqiangxin capsule, enalapril, shenmai injection, and hydrochlorothiazide, significantly reduced heart dilatation and venous congestion (Fig. 1). The reduction $\%$ of enlarged heart was 20\%-90\% for LCZ696, -1\%-70\% for digoxin, 20\%-67\% for irbesartan, 1\%-63\% for metoprolol, 12\%-101\% for qiliqiangxin capsule, $16 \%-90 \%$ for enalapril, $17 \%-98 \%$ for shenmai injection, and $12 \%-75 \%$ for hydrochlorothiazide, respectively. Statistically significant preventive effects on zebrafish heart dilatation were observed for LCZ696, digoxin, irbesartan, metoprolol, qiliqiangxin capsule, enalapril, shenmai injection, and hydrochlorothiazide (Table 1 and Fig. 2).

The reduction $\%$ of venous congestion was $7 \%-89 \%$ for LCZ696, 5\%-84\% for digoxin, 27\%-49\% for irbesartan, $2 \%-43 \%$ for metoprolol, $2 \%-75 \%$ for qiliqiangxin capsule, $7 \%-94 \%$ for enalapril, $16 \%-83 \%$ for shenmai injection, and $-3 \%$ to $73 \%$ for hydrochlorothiazide, respectively. Statistically significant preventive effects on zebrafish venous congestion were observed for LCZ696, digoxin, irbesartan, metoprolol, qiliqiangxin capsule, enalapril, shenmai injection, and hydrochlorothiazide (Table 1 and Fig. 3).

The increase in $\%$ of cardiac output was $0 \%-123 \%$ for LCZ696, 7\%-50\% for digoxin, $-2 \%$ to $62 \%$ for irbesartan, $2 \%-56 \%$ for metoprolol, $10 \%-90 \%$ for qiliqiangxin capsule, $-3 \%$ to $51 \%$ for enalapril, $27 \%-81 \%$ for shenmai injection, 
Table 1. Drug Efficacy on Heart Dilatation, Venous Congestion, Cardiac Output, and Blood Flow Dynamics in the Zebrafish Heart Failure Model

\begin{tabular}{|c|c|c|c|c|c|}
\hline Drugs & Concentrations/dosages & $\begin{array}{c}\text { Efficacy on heart } \\
\text { dilatation }(\%)\end{array}$ & $\begin{array}{c}\text { Efficacy on venous } \\
\text { congestion }(\%)\end{array}$ & $\begin{array}{c}\text { Efficacy on } \\
\text { cardiac output }(\%)\end{array}$ & $\begin{array}{l}\text { Efficacy on blood } \\
\text { flow dynamics }(\%)\end{array}$ \\
\hline \multirow[t]{9}{*}{ LCZ696 } & $0.005 \mu \mathrm{g} \cdot \mathrm{mL}^{-1}$ & 20 & 7 & 0 & 6 \\
\hline & $0.01 \mu \mathrm{g} . \mathrm{mL}^{-1}$ & $31^{\mathrm{a}}$ & 17 & 13 & 14 \\
\hline & $0.025 \mu \mathrm{g} \cdot \mathrm{mL}^{-1}$ & $48^{\mathrm{b}}$ & $34^{\mathrm{a}}$ & 23 & 16 \\
\hline & $0.05 \mu \mathrm{g} . \mathrm{mL}^{-1}$ & $64^{\mathrm{c}}$ & $51^{\mathrm{c}}$ & $44^{\mathrm{b}}$ & $36^{\mathrm{a}}$ \\
\hline & $0.1 \mu \mathrm{g} \cdot \mathrm{mL}^{-1}$ & $71^{\mathrm{c}}$ & $79^{\mathrm{c}}$ & $92^{\mathrm{c}}$ & $59^{c}$ \\
\hline & $0.25 \mu \mathrm{g} \cdot \mathrm{mL}^{-1}$ & $80^{\mathrm{c}}$ & $81^{\mathrm{c}}$ & $123^{\mathrm{c}}$ & $66^{c}$ \\
\hline & $0.5 \mu \mathrm{g} \cdot \mathrm{mL}^{-1}$ & $90^{\mathrm{c}}$ & $89^{c}$ & $65^{b}$ & $26^{\mathrm{b}}$ \\
\hline & $1 \mu \mathrm{g} \cdot \mathrm{mL}^{-1}$ & $51^{\mathrm{c}}$ & $36^{\mathrm{b}}$ & 18 & 14 \\
\hline & $2.5 \mu \mathrm{g} \cdot \mathrm{mL}^{-1}$ & $39^{\mathrm{a}}$ & 22 & -7 & 9 \\
\hline \multirow[t]{10}{*}{ Digoxin } & $0.01 \mu \mathrm{g} \cdot \mathrm{mL}^{-1}$ & -1 & 5 & 7 & 11 \\
\hline & $0.025 \mu \mathrm{g} \cdot \mathrm{mL}^{-1}$ & 11 & 22 & 11 & $17^{\mathrm{a}}$ \\
\hline & $0.05 \mu \mathrm{g} . \mathrm{mL}^{-1}$ & 16 & 27 & $27^{\mathrm{a}}$ & $20^{\mathrm{b}}$ \\
\hline & $0.1 \mu \mathrm{g} \cdot \mathrm{mL}^{-1}$ & $35^{\mathrm{a}}$ & $35^{\mathrm{a}}$ & $34^{\mathrm{b}}$ & $28^{\mathrm{b}}$ \\
\hline & $0.25 \mu \mathrm{g} \cdot \mathrm{mL}^{-1}$ & $47^{\mathrm{b}}$ & $45^{\mathrm{b}}$ & $50^{\mathrm{c}}$ & $30^{\mathrm{c}}$ \\
\hline & $0.5 \mu \mathrm{g} . \mathrm{mL}^{-1}$ & $53^{\mathrm{b}}$ & $73^{\mathrm{c}}$ & $40^{\mathrm{b}}$ & $28^{\mathrm{b}}$ \\
\hline & $1 \mu \mathrm{g} \cdot \mathrm{mL}^{-1}$ & $56^{\mathrm{b}}$ & $84^{\mathrm{c}}$ & $36^{\mathrm{c}}$ & $18^{\mathrm{a}}$ \\
\hline & $2.5 \mu \mathrm{g} \cdot \mathrm{mL}^{-1}$ & $59^{c}$ & $73^{\mathrm{c}}$ & $25^{\mathrm{a}}$ & $14^{\mathrm{a}}$ \\
\hline & $5 \mu \mathrm{g} \cdot \mathrm{mL}^{-1}$ & $60^{c}$ & $35^{\mathrm{b}}$ & 20 & 9 \\
\hline & $10 \mu \mathrm{g} \cdot \mathrm{mL}^{-1}$ & $70^{c}$ & 27 & -2 & 5 \\
\hline \multirow[t]{7}{*}{ Irbesartan } & $0.1 \mu \mathrm{g} \cdot \mathrm{mL}^{-1}$ & 20 & $27^{\mathrm{a}}$ & -2 & -1 \\
\hline & $0.25 \mu \mathrm{g} \cdot \mathrm{mL}^{-1}$ & 24 & $34^{\mathrm{a}}$ & $22^{\mathrm{a}}$ & 9 \\
\hline & $0.5 \mu \mathrm{g} \cdot \mathrm{mL}^{-1}$ & $30^{\mathrm{a}}$ & $36^{\mathrm{b}}$ & $25^{\mathrm{a}}$ & 15 \\
\hline & $1 \mu \mathrm{g} \cdot \mathrm{mL}^{-1}$ & $36^{\mathrm{a}}$ & $40^{\mathrm{b}}$ & $28^{\mathrm{a}}$ & $16^{\mathrm{a}}$ \\
\hline & $2.5 \mu \mathrm{g} \cdot \mathrm{mL}^{-1}$ & $38^{\mathrm{b}}$ & $41^{\mathrm{c}}$ & $33^{\mathrm{a}}$ & $23^{\mathrm{a}}$ \\
\hline & $5 \mu \mathrm{g} \cdot \mathrm{mL}^{-1}$ & $43^{\mathrm{c}}$ & $43^{b}$ & $55^{\mathrm{c}}$ & $30^{\mathrm{b}}$ \\
\hline & $10 \mu \mathrm{g} \cdot \mathrm{mL}^{-1}$ & $67^{\mathrm{c}}$ & $49^{c}$ & $62^{\mathrm{c}}$ & $31^{\mathrm{b}}$ \\
\hline \multirow[t]{9}{*}{ Metoprolol } & $0.025 \mu \mathrm{g} \cdot \mathrm{mL}^{-1}$ & 1 & 2 & 4 & 0 \\
\hline & $0.05 \mu \mathrm{g} \cdot \mathrm{mL}^{-1}$ & $19^{\mathrm{a}}$ & 7 & 2 & 1 \\
\hline & $0.1 \mu \mathrm{g} \cdot \mathrm{mL}^{-1}$ & $25^{\mathrm{a}}$ & 11 & 11 & 6 \\
\hline & $0.25 \mu \mathrm{g} \cdot \mathrm{mL}^{-1}$ & $31^{\mathrm{b}}$ & 26 & $30^{\mathrm{c}}$ & $13^{\mathrm{a}}$ \\
\hline & $0.5 \mu \mathrm{g} \cdot \mathrm{mL}^{-1}$ & $34^{\mathrm{b}}$ & $29^{\mathrm{a}}$ & $35^{\mathrm{c}}$ & $17^{\mathrm{a}}$ \\
\hline & $1 \mu \mathrm{g} \cdot \mathrm{mL}^{-1}$ & $63^{c}$ & $35^{\mathrm{a}}$ & $38^{\mathrm{c}}$ & $17^{\mathrm{a}}$ \\
\hline & $2.5 \mu \mathrm{g} \cdot \mathrm{mL}^{-1}$ & $40^{c}$ & $41^{\mathrm{b}}$ & $40^{\mathrm{c}}$ & $20^{\mathrm{a}}$ \\
\hline & $5 \mu \mathrm{g} \cdot \mathrm{mL}^{-1}$ & $27^{\mathrm{b}}$ & $43^{\mathrm{b}}$ & $56^{\mathrm{c}}$ & $29^{c}$ \\
\hline & $10 \mu \mathrm{g} \cdot \mathrm{mL}^{-1}$ & 6 & 15 & 13 & 1 \\
\hline \multirow[t]{7}{*}{ Qiliqiangxin capsule } & $2.5 \mu \mathrm{g} \cdot \mathrm{mL}^{-1}$ & 12 & 2 & 10 & 1 \\
\hline & $5 \mu \mathrm{g} \cdot \mathrm{mL}^{-1}$ & $47^{\mathrm{a}}$ & $25^{\mathrm{a}}$ & $39^{\mathrm{b}}$ & 12 \\
\hline & $10 \mu \mathrm{g} \cdot \mathrm{mL}^{-1}$ & $72^{\mathrm{c}}$ & $46^{\mathrm{c}}$ & $65^{\mathrm{c}}$ & $41^{\mathrm{b}}$ \\
\hline & $25 \mu \mathrm{g} \cdot \mathrm{mL}^{-1}$ & $101^{\mathrm{c}}$ & $75^{\mathrm{c}}$ & $90^{\mathrm{c}}$ & $66^{\mathrm{c}}$ \\
\hline & $50 \mu \mathrm{g} \cdot \mathrm{mL}^{-1}$ & $87^{\mathrm{c}}$ & $52^{\mathrm{c}}$ & $62^{\mathrm{c}}$ & $34^{\mathrm{a}}$ \\
\hline & $100 \mu \mathrm{g} \cdot \mathrm{mL}^{-1}$ & $76^{\mathrm{c}}$ & $45^{\mathrm{c}}$ & $44^{\mathrm{a}}$ & $27^{\mathrm{a}}$ \\
\hline & $250 \mu \mathrm{g} \cdot \mathrm{mL}^{-1}$ & $44^{\mathrm{a}}$ & 2 & 17 & 2 \\
\hline \multirow[t]{6}{*}{ Enalapril } & $5 \mu \mathrm{g} \cdot \mathrm{mL}^{-1}$ & 16 & 7 & -3 & 1 \\
\hline & $10 \mu \mathrm{g} \cdot \mathrm{mL}^{-1}$ & $31^{\mathrm{a}}$ & $34^{\mathrm{a}}$ & $34^{\mathrm{b}}$ & $26^{\mathrm{b}}$ \\
\hline & $25 \mu \mathrm{g} \cdot \mathrm{mL}^{-1}$ & $50^{\mathrm{b}}$ & $56^{\mathrm{c}}$ & $51^{\mathrm{c}}$ & $33^{\mathrm{b}}$ \\
\hline & $50 \mu \mathrm{g} \cdot \mathrm{mL}^{-1}$ & $54^{\mathrm{b}}$ & $60^{c}$ & $51^{\mathrm{c}}$ & $42^{c}$ \\
\hline & $100 \mu \mathrm{g} \cdot \mathrm{mL}^{-1}$ & $66^{c}$ & $87^{\mathrm{c}}$ & $33^{b}$ & $20^{\mathrm{a}}$ \\
\hline & $250 \mu \mathrm{g} \cdot \mathrm{mL}^{-1}$ & $90^{c}$ & $94^{\mathrm{c}}$ & 19 & 19 \\
\hline \multirow[t]{6}{*}{ Shenmai injection } & $0.3125 \mathrm{ng}$ & 17 & 16 & $27^{\mathrm{a}}$ & $19^{\mathrm{a}}$ \\
\hline & $0.625 \mathrm{ng}$ & $38^{\mathrm{a}}$ & $39^{\mathrm{c}}$ & $48^{\mathrm{c}}$ & $23^{\mathrm{a}}$ \\
\hline & $1.25 \mathrm{ng}$ & $75^{\mathrm{c}}$ & $62^{c}$ & $52^{\mathrm{c}}$ & $26^{\mathrm{a}}$ \\
\hline & $2.5 \mathrm{ng}$ & $98^{\mathrm{b}}$ & $83^{\mathrm{c}}$ & $72^{c}$ & $31^{\mathrm{b}}$ \\
\hline & $5 \mathrm{ng}$ & $60^{\mathrm{b}}$ & $63^{\mathrm{c}}$ & $81^{\mathrm{c}}$ & $35^{\mathrm{b}}$ \\
\hline & $10 \mathrm{ng}$ & 1 & $49^{\mathrm{c}}$ & $25^{\mathrm{a}}$ & 9 \\
\hline \multirow[t]{12}{*}{ Hydrochlorothiazide } & $0.01 \mu \mathrm{g} \cdot \mathrm{mL}^{-1}$ & 12 & -3 & - & - \\
\hline & $0.025 \mu \mathrm{g} \cdot \mathrm{mL}^{-1}$ & 14 & 14 & - & - \\
\hline & $0.05 \mu \mathrm{g} \cdot \mathrm{mL}^{-1}$ & $39^{\mathrm{a}}$ & $32^{\mathrm{b}}$ & - & - \\
\hline & $0.1 \mu \mathrm{g} \cdot \mathrm{mL}^{-1}$ & $46^{\mathrm{a}}$ & $43^{b}$ & 18 & 5 \\
\hline & $0.25 \mu \mathrm{g} \cdot \mathrm{mL}^{-1}$ & $49^{\mathrm{a}}$ & $55^{\mathrm{c}}$ & $35^{\mathrm{b}}$ & 23 \\
\hline & $0.5 \mu \mathrm{g} . \mathrm{mL}^{-1}$ & $56^{\mathrm{b}}$ & $60^{c}$ & $53^{\mathrm{b}}$ & $33^{\mathrm{a}}$ \\
\hline & $1 \mu \mathrm{g} \cdot \mathrm{mL}^{-1}$ & $62^{\mathrm{b}}$ & $62^{c}$ & $67^{\mathrm{b}}$ & $43^{\mathrm{b}}$ \\
\hline & $2.5 \mu \mathrm{g} \cdot \mathrm{mL}^{-1}$ & $68^{b}$ & $63^{c}$ & $69^{c}$ & $49^{c}$ \\
\hline & $5 \mu \mathrm{g} \cdot \mathrm{mL}^{-1}$ & $70^{\mathrm{b}}$ & $67^{\mathrm{c}}$ & $84^{\mathrm{c}}$ & $53^{c}$ \\
\hline & $10 \mu \mathrm{g} \cdot \mathrm{mL}^{-1}$ & $75^{c}$ & $73^{c}$ & $68^{\mathrm{c}}$ & $52^{\mathrm{c}}$ \\
\hline & $25 \mu \mathrm{g} \cdot \mathrm{mL}^{-1}$ & $43^{\mathrm{a}}$ & $47^{\mathrm{c}}$ & $56^{\mathrm{c}}$ & $44^{\mathrm{b}}$ \\
\hline & $50 \mu \mathrm{g} \cdot \mathrm{mL}^{-1}$ & 33 & $40^{\circ}$ & $38^{\mathrm{b}}$ & $37^{\mathrm{D}}$ \\
\hline
\end{tabular}

Compared with vehicle control: ${ }^{\mathrm{a}} p<0.05,{ }^{\mathrm{b}} p<0.01$, and ${ }^{\mathrm{c}} p<0.001$. 

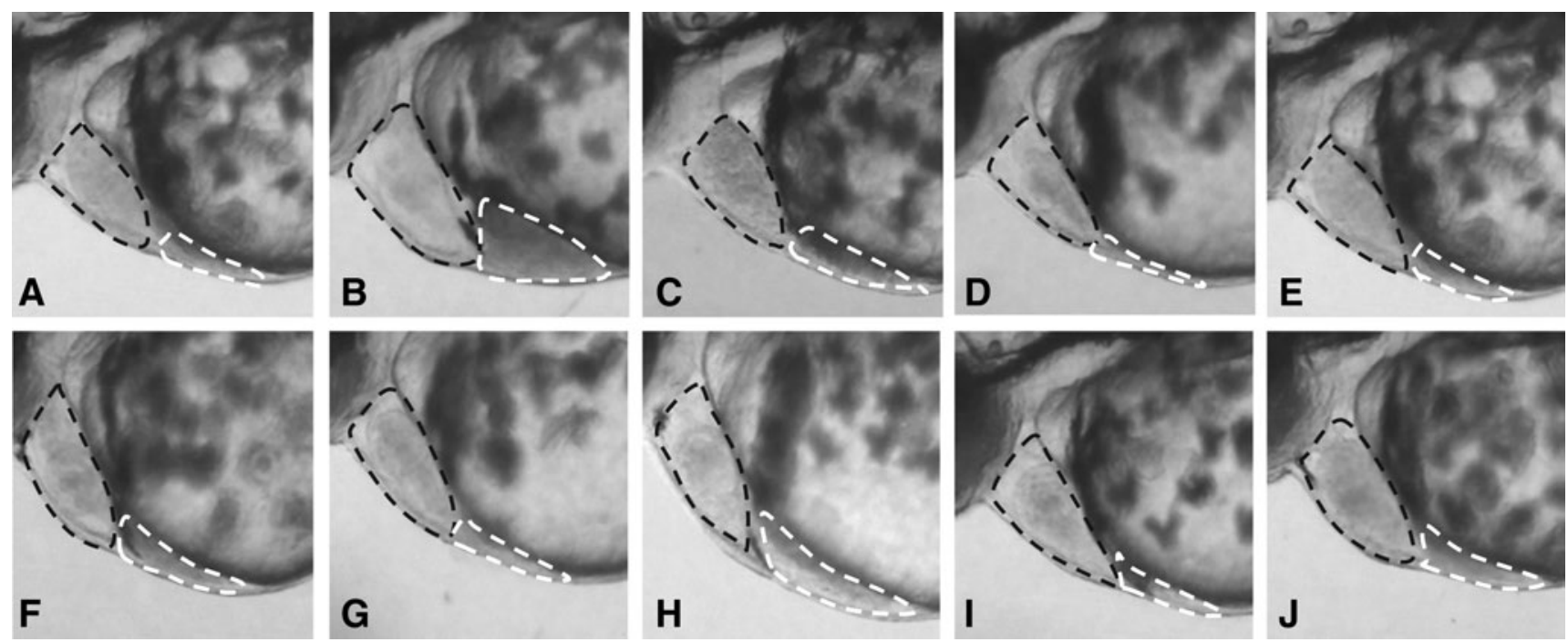

FIG. 1. Reduced heart dilatation and venous congestion in heart failure zebrafish treated with human therapeutic drugs for 4.5 h. (A) Vehicle-treated zebrafish; (B) zebrafish treated with verapamil alone; and heart failure zebrafish treated with human heart failure therapeutics, LCZ696, digoxin, irbesartan, metoprolol, qiliqiangxin capsule, enalapril, shenmai injection, and hydrochlorothiazide, resulting in significantly decreased heart dilatation and venous congestion (C-J). Heart and heart dilatation are shown in black dotted lines, and venus and venous congestion in white dotted lines.

and $18 \%-84 \%$ for hydrochlorothiazide, respectively. Statistically significant preventive effects on zebrafish venous congestion were observed for LCZ696, digoxin, irbesartan, metoprolol, qiliqiangxin capsule, enalapril, shenmai injection, and hydrochlorothiazide (Table 1 and Fig. 4).

The increase in $\%$ of blood flow velocity was $6 \%-66 \%$ for LCZ696, $11 \%-30 \%$ for digoxin, $-1 \%$ to $1 \%$ for irbesartan, $0 \%-29 \%$ for metoprolol, $1 \%-66 \%$ for qiliqiangxin capsule, $1 \%-42 \%$ for enalapril, $19 \%-35 \%$ for shenmai injection, and $5 \%-53 \%$ for hydrochlorothiazide, respectively. Statistically significant preventive effects on zebrafish venous congestion were observed for LCZ696, digoxin, irbesartan, metoprolol, qiliqiangxin capsule, enalapril, shenmai injection, and hydrochlorothiazide (Table 1 and Fig. 5).

\section{Discussion}

This study aimed to develop and validate a live zebrafish heart failure model for rapid in vivo screening and efficacy assessment of heart failure therapeutic drugs. Zebrafish is emerging as a predictive animal model for in vivo assessment of drug efficacy, toxicity, and safety. ${ }^{21,24-27}$ We use zebrafish because of their many advantages such as short generation times, amenability for large-scale screening, high fecundity, ease of in vitro fertilization, and transparency. ${ }^{28-30}$ Another important advantage of the zebrafish as an animal model is that the morphological and molecular bases of tissues and organs are either identical or similar to other vertebrates, including humans. ${ }^{22,31}$

In this study, we have selected verapamil to treat larval zebrafish at an optimum developmental stage of $2 \mathrm{dpf}$ and optimized verapamil treatment concentration and treatment time period to develop a live zebrafish heart failure model with quantitative analysis. Zebrafish at $2 \mathrm{dpf}$ were treated with verapamil at a concentration of $200 \mu \mathrm{M}$ for a time period of $30 \mathrm{~min}$, which were determined as optimum conditions for zebrafish heart failure model development. Heart dilatation and venous congestion in the live zebrafish were visually tracked and confirmed under a dissecting stereomicroscope. The cardiac output and blood flow dynamics of zebrafish were subjected to video recording under a Zebralab Blood Flow System. We found that larval zebrafish treated with verapamil under these optimum conditions developed pericardial edema and venous blood congestion with reduced cardiac output and blood flow velocity, similar to the pathophysiology observed in human heart failure patients, ${ }^{32}$ indicating that verapamil could induce heart failure in larval zebrafish. This zebrafish heart failure model is stable and highly reproducible with $\mathrm{CV}$ values of intraexperiments, interexperiments, and day-to-day variations $\leq 25 \%$ (data not shown).

Our findings were supported by an earlier preliminary study that demonstrated that treatment of zebrafish at 2-3 dpf with verapamil could cause bradycardia, pericardial edema, and circulation defects. ${ }^{24}$ Verapamil belongs to the phenylalkylamine class of L-type $\mathrm{Ca}^{2+}$ channel blockers and is used to treat cardiac arrhythmias, hypertension, and angina. ${ }^{33}$ Overdoses of $\mathrm{Ca}^{2+}$ channel blockers cause rapid development of hypotension, bradydysrhythmia, and cardiac arrest. ${ }^{34}$ Verapamil was reported to cause pericardial effusion, decreased systolic function, conduction disturbances, and heart block in humans. Consistent with the cardiovascular toxicity found in humans, this drug also induces the same or similar cardiovascular toxicity in zebrafish. ${ }^{24}$ Verapamil decreases the frequency of calcium oscillation in the zebrafish heart. Subsequently, verapamil's inhibitory effect on cytosolic calcium reduces myocardial heartbeat. It is expected that verapamil also decreases the amplitude of cytosolic calcium oscillation in zebrafish heart.

To further validate the zebrafish heart failure model developed in this report for pharmaceutical testing, six FDAapproved heart failure therapeutic drugs (LCZ696, digoxin, irbesartan, metoprolol, enalapril, and hydrochlorothiazide) and two CFDA-approved heart failure therapeutic medicines (qiliqiangxin capsule and shenmai injection) were chosen and 

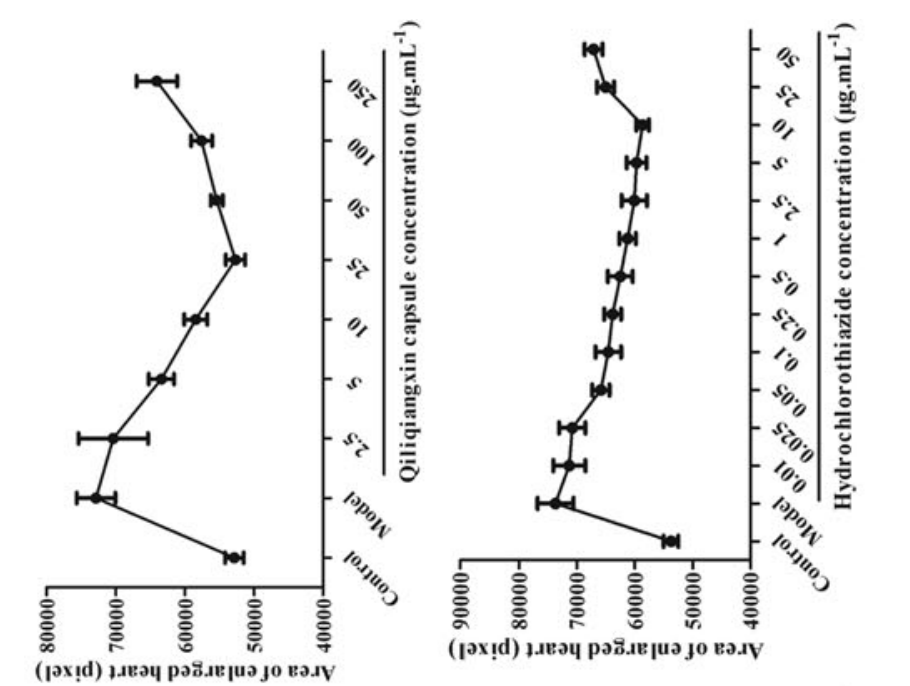

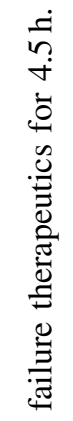
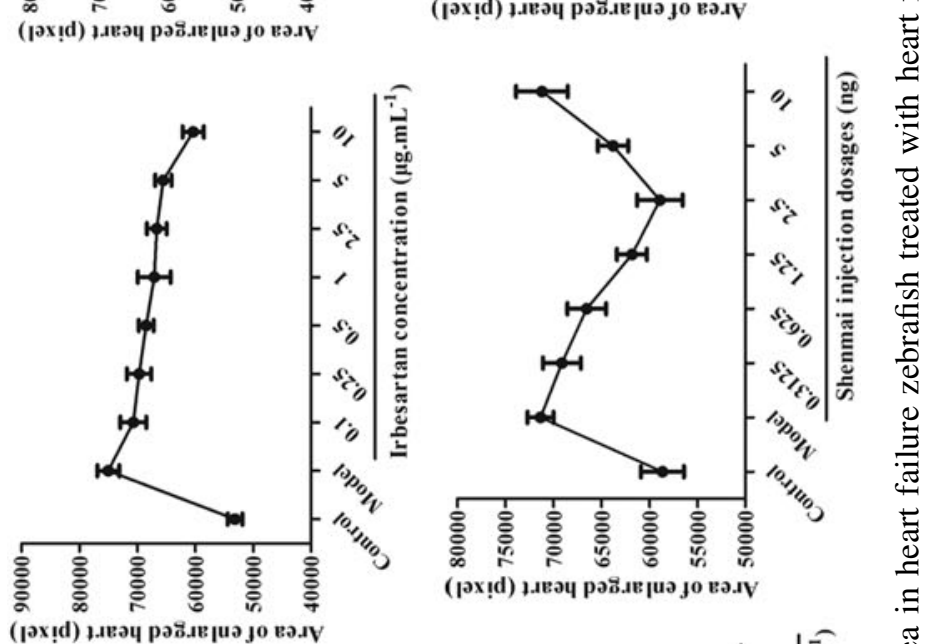

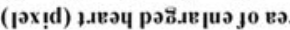
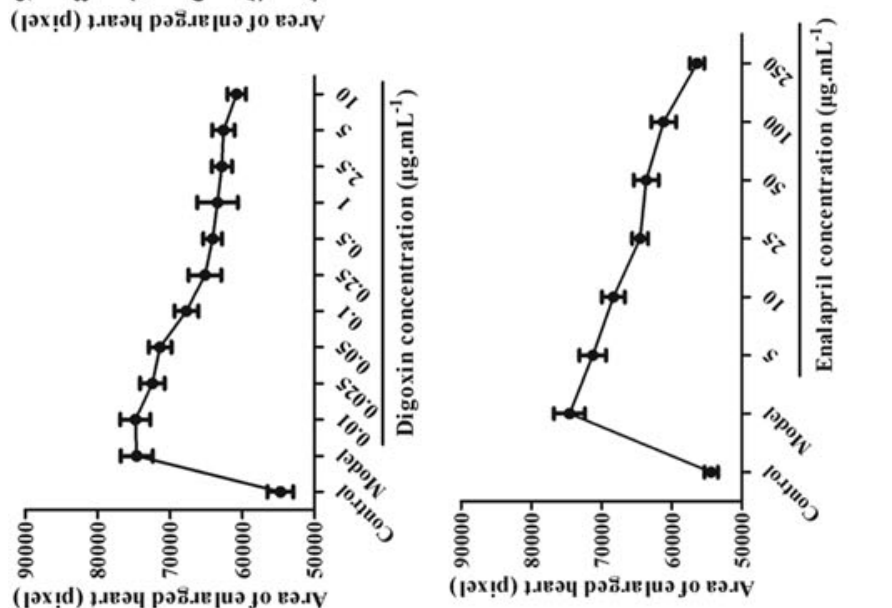

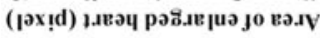
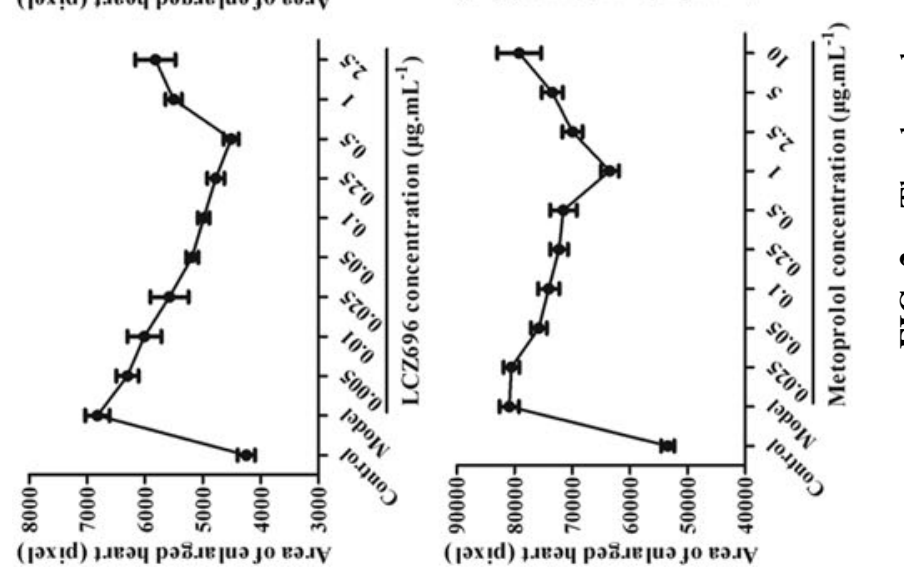

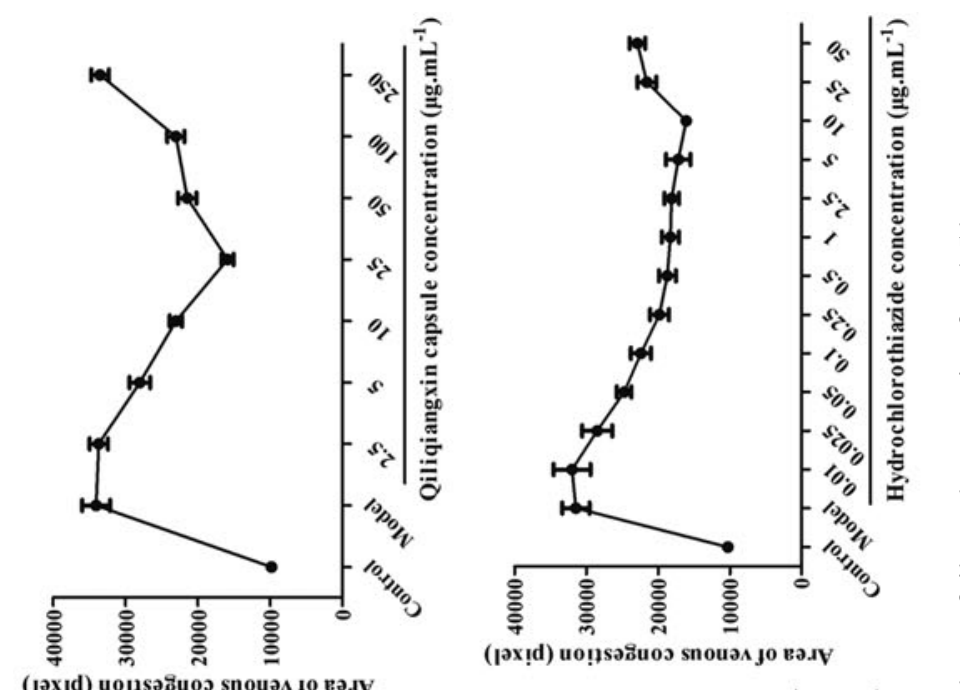

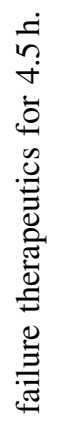

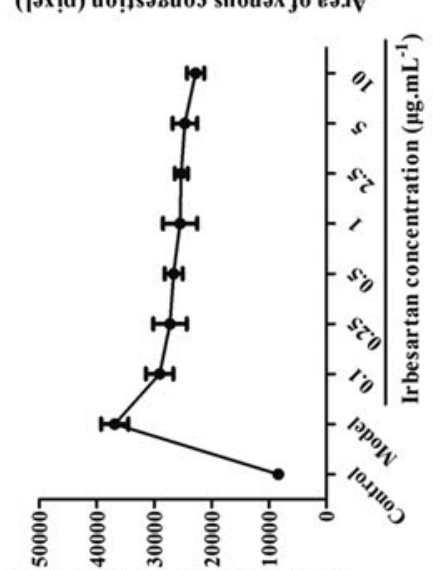

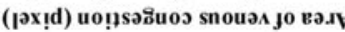

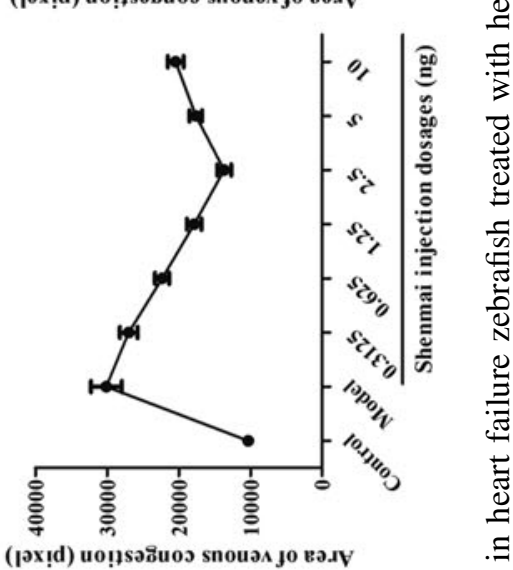

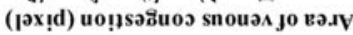

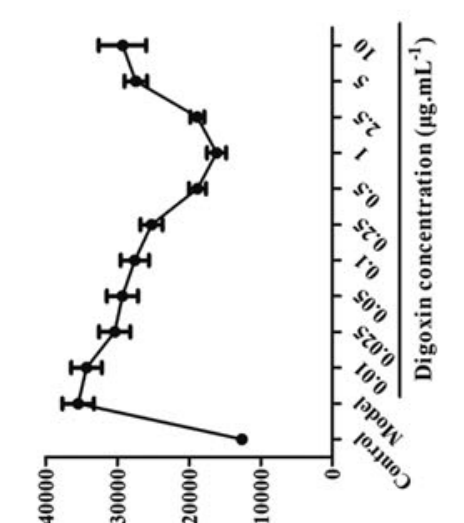

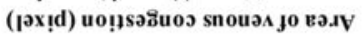

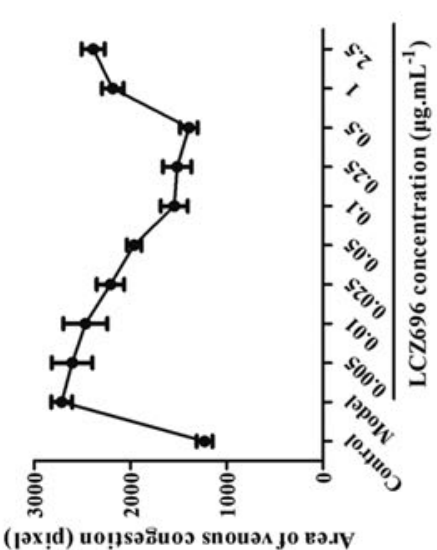

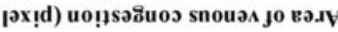
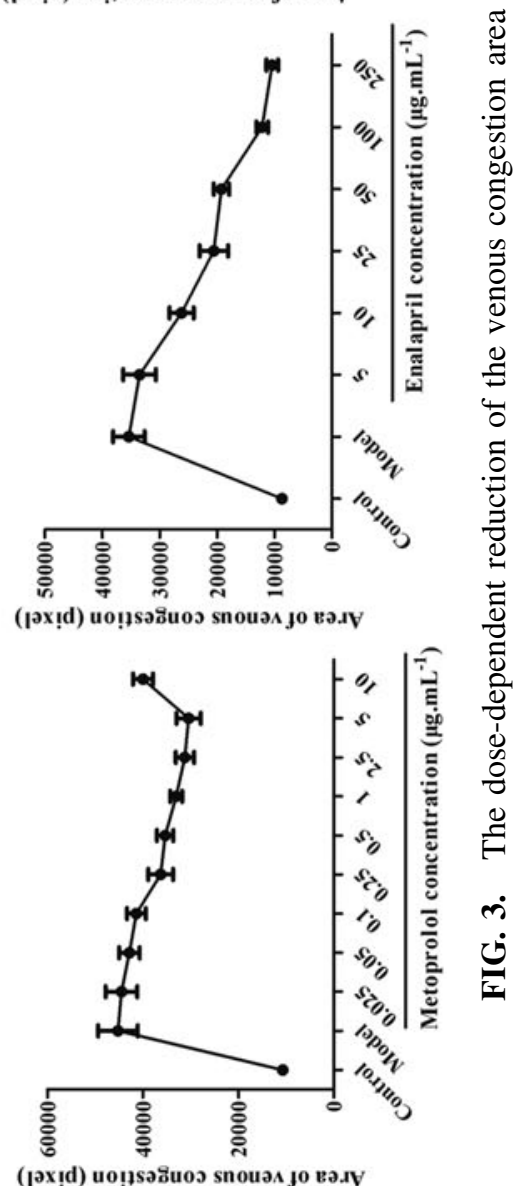

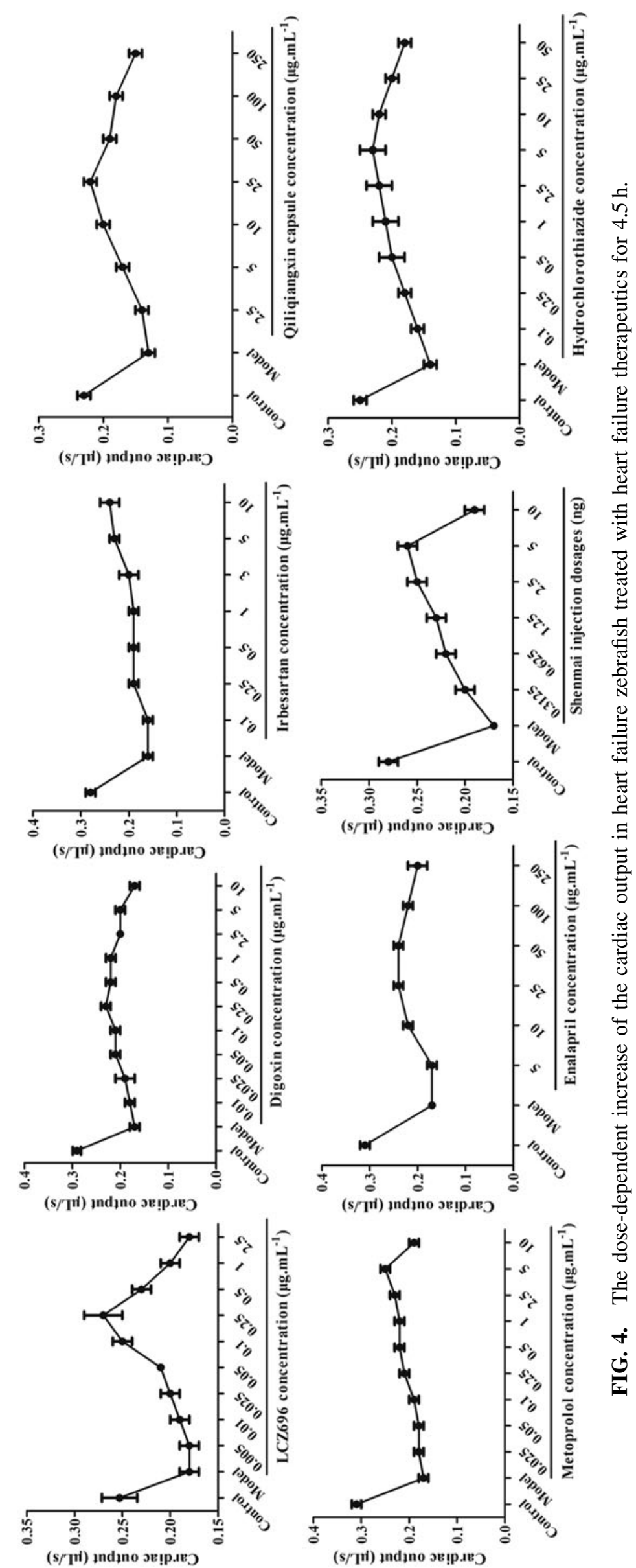

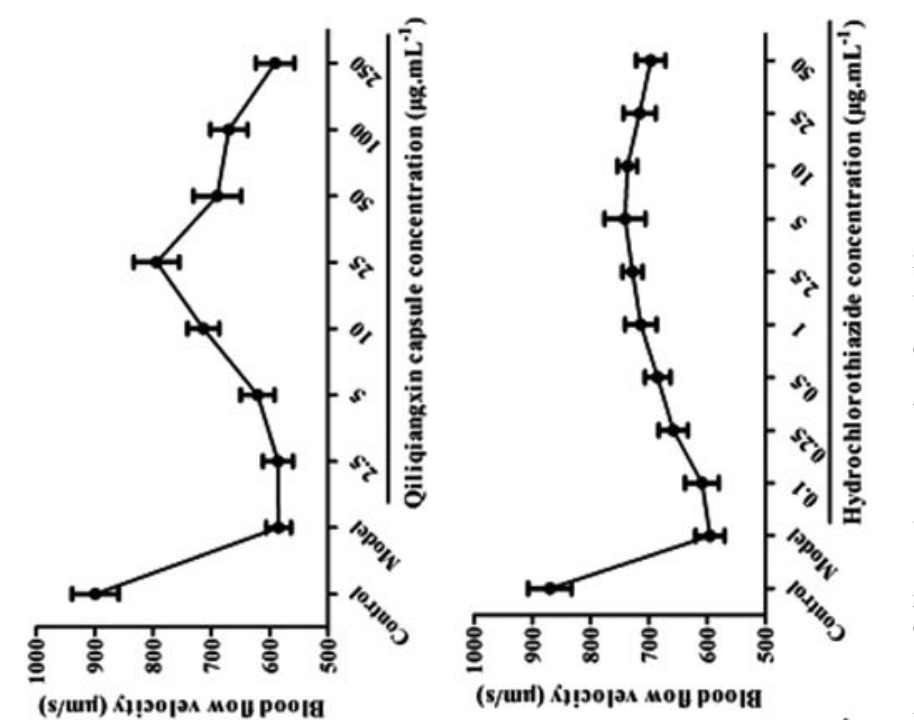

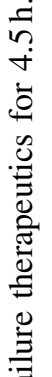

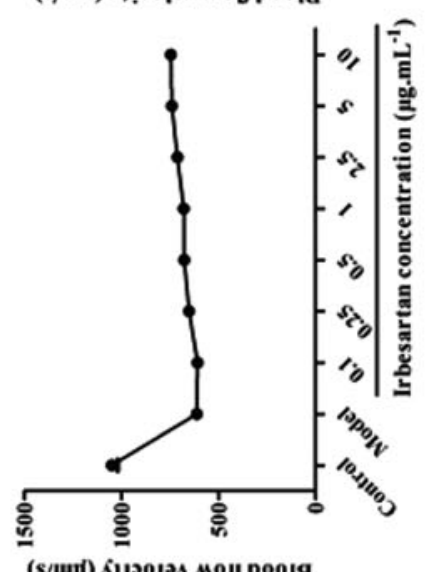

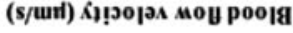

(s/uii) Аџ!วојอง моч роо|g
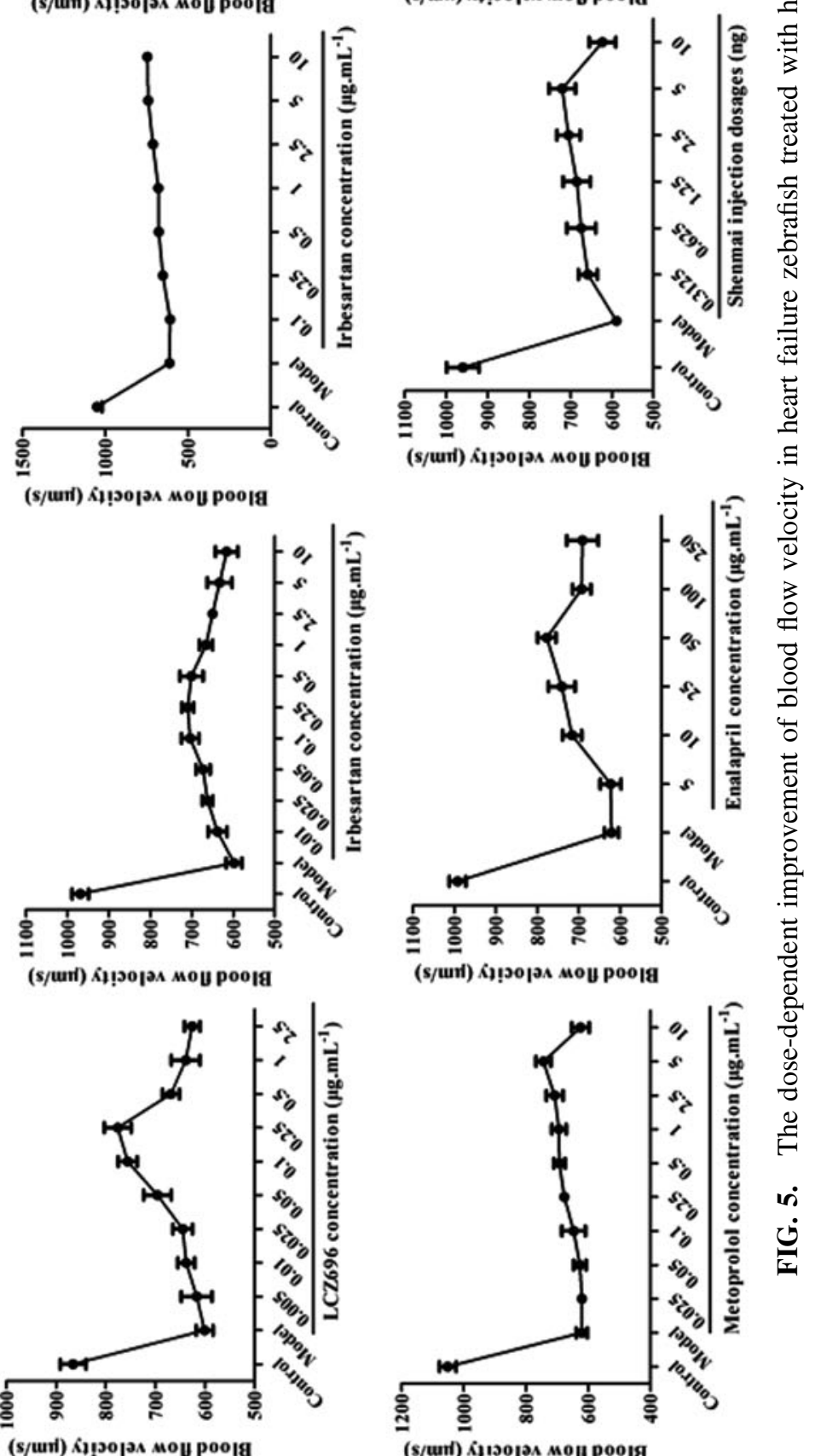
tested in this model for their preventive and therapeutic effects on heart failure. LCZ696 is an angiotensin receptor and neprilysin inhibitor ${ }^{35}$; digoxin is an adenosine diphosphate inhibitor $^{36}$; irbesartan is a long-acting AIIRA with high selectivity for the AT1 receptor site ${ }^{37}$; metoprolol is a selective $\beta 1$ receptor blocker ${ }^{38}$; enalapril is an angiotensin-converting enzyme inhibitor $^{39,40}$; and hydrochlorothiazide is a diuretic medication often used to treat high blood pressure and swelling due to fluid buildup. ${ }^{41}$ Qiliqiangxin capsule (QL) was developed under the guidance of the Traditional Chinese Medicine (TCM) theory of collateral disease. ${ }^{42}$ It is a drug of TCM for the treatment of heart failure, registered in the Chinese State Food and Drug Administration (SFDA) in 1996, and has been used in clinical practice for more than a decade. Previous studies have shown that QL was able to inhibit Ang II and ALD levels, improve hemodynamics and cardiac function, inhibit ventricular remodeling, ${ }^{42}$ and reduce the concentration of plasma vasopressin (AVP) and cardiac stress. ${ }^{43}$ Shenmai injection was formulated based on the classic recipe, Shengmai Powder, with modifications. It consists of Radix Ginseng and Radix Ophiopogonis and possesses the functions of supplementing qi, nourishing yin, redeeming yang, reversing deterioration, restoring pulse, and stabilizing shock. Modern studies have found that it could enhance heart function and improve the symptoms of heart failure, which may be related to its effects in increasing coronary blood flow, reducing myocardial oxygen consumption, improving myocardial energy metabolism, and blood coagulation. ${ }^{44,45}$

All 6 human heart failure therapeutic drugs significantly reduced heart dilatation and venous congestion and increased cardiac output and blood flow dynamics in the zebrafish heart failure model after $4.5 \mathrm{~h}$ of treatment, indicating that the zebrafish heart failure model developed here is suitable for in vivo screening and assessment of oral and injectable heart failure therapeutic drugs, no matter if used as a single compound medicine or as herb extracts. Our results also further support that drugs derived from TCMs are valuable in the prevention and treatment of heart failure diseases.

The zebrafish as a model organism offers opportunities for rapid in vivo drug discovery and development. The larval zebrafish heart failure model developed in this study was a live and physiology-associated whole-animal assay. This model is a useful tool for whole-animal heart failure studies and for screening agents of heart failure. The use of zebrafish as an alternative animal model for heart failure therapeutic drug screening and assessment could save time, decrease costs, and reduce drug failure at later stages of drug development. Extended studies are in progress to define heart histopathology in verapamil-treated zebrafish using gene expression profiling and other biochemical and molecular biology techniques in this heart failure model. We are also further validating this model using more human drugs and developing this model into a higher throughput screening or even an automatic assay system. We believe that the power of zebrafish models and assays could be better utilized to advance the basic and translational research and drug discovery and development, including in the field of heart failure.

\section{Conclusions}

This study developed and validated a zebrafish heart failure model that could be used for in vivo screening and efficacy assessment of heart failure therapeutic drugs. This conventional zebrafish heart failure model is predictive, easily available, less expensive with a short testing time, and could speed up heart failure therapeutic drug research and development.

\section{Acknowledgments}

Xiao-Yu Zhu, Ping Li, and Chun-Qi Li designed the research; Xiao-Yu Zhu, Hua Yang, Sheng-Ya Guo, Bo Xia, and $\mathrm{Ru}-$ Shun Song performed the research; Xiao-Yu Zhu, Si-Qi Wu, Sheng-Ya Guo, Hua Yang, and Bo Xia analyzed the data; and Xiao-Yu Zhu and Chun-Qi Li wrote the article. This work was sponsored, in part, by the Zhejiang Provincial Key Science \& Technology Project Grant (2014C03009) and the National Key Science and Technology Project Grant of the 12th 5-year program of China (2011ZX09301-003).

\section{Disclosure Statement}

No competing financial interests exist.

\section{References}

1. The American Heart Association Statistics Committee and Stroke Statistics Subcommittee: Heart disease and stroke statistics-2012 update: a report from the American Heart Association. Circulation 2012;125:e2-e220.

2. McMurray JJV, Pfeffer MA. Heart failure. Lancet 2005; 365:1877-1889.

3. Feenstra J, Grobbee D, Remme W, Stricker B. Drug-induced heart failure. J Am Coll Cardiol 1999;33:1152-1162.

4. Gharib MI, Burnett AK. Chemotherapy-induced cardiotoxicity: current practice and prospects of prophylaxis. Eur J Heart Fail 2014;4:235-242.

5. Delgado DR, Nawar MA, Zewail AM, et al. Cyclooxygenase2 inhibitor treatment improves left ventricular function and mortality in a murine model of doxorubicin-induced heart failure. Circulation 2004;109:1428-1433.

6. Zon LI, Peterson RT. In vivo drug discovery in the zebrafish. Nat Rev Drug Dis 2005;4:35-44.

7. Jeroen B. Zebrafish as a model to study cardiac development and human cardiac disease. Cardiovasc Res 2011;91: 279-288.

8. Hecker L, Khait L, Sessions S K, et al. Functional evaluation of isolated zebrafish hearts. Zebrafish 2008;5:319-322.

9. Langheinrich U, Vacun G, Wagner T. Zebrafish embryos express an orthologue of HERG and are sensitive toward a range of QT-prolonging drugs inducing severe arrhythmia. Toxicol Appl Pharmacol 2003;193:370-382.

10. Hassel D, Scholz EP, Trano N, et al. Deficient zebrafish Ether-à-Go-Go-related gene channel gating causes shortQT syndrome in zebrafish reggae mutants. Circulation 2008; $117: 866$

11. Verkerk AO, Remme CA. Zebrafish: a novel research tool for cardiac (patho)electrophysiology and ion channel disorders. Front Physiol 2012;3:255.

12. Milan DJ, Kim AM, Winterfield JR, et al. Drug-sensitized zebrafish screen identifies multiple genes, including GINS3, as regulators of myocardial repolarization. Circulation 2009; 120:553.

13. Gu G, Na Y, Chung H, et al. Zebrafish Larvae Model of Dilated Cardiomyopathy Induced by Terfenadine. Korean Circ J 2017;47:960-969. 
14. Shi X, Verma S, Yun J, et al. Effect of empagliflozin on cardiac biomarkers in a zebrafish model of heart failure: clues to the EMPA-REG OUTCOME trial?. Mol Cell Biochem 2017;433:97-102.

15. Kim JY, Kim HH, Cho KH. Acute cardiovascular toxicity of sterilizers, PHMG, and PGH: severe inflammation in human cells and heart failure in zebrafish. Cardiovasc Toxicol 2013;13:148-160.

16. Huang CC, Monte A, Cook JM, Kabir MS, Peterson KP. Zebrafish heart failure models for the evaluation of chemical probes and drugs. Assay Drug Dev Technol 2013;11:561-572.

17. Huang CC, Chen PC, Huang CW, Yu J. Aristolochic Acid induces heart failure in zebrafish embryos that is mediated by inflammation. Toxicol Sci 2007;100:486.

18. Kimmel CB, Ballard WW, Kimmel SR, Ullmann B, Schilling TF. Stages of embryonic development of the zebrafish. Dev Dynam 1995;203:253-310.

19. Zhou J, Xu YQ, Guo SY, Li CQ. Rapid analysis of hypolipidemic drugs in a live zebrafish assay. J Pharmacol Toxicol Methods 2015;72:47-52.

20. Listed N. Biomarkers, genomics, telemetry, computational biology, and zebrafish: will one of these solve the problems of post-myocardial infarction heart failure?. Eur Heart $\mathbf{J}$ 2014;35:57-58.

21. Zhu XY, Liu HC, Guo SY, et al. A zebrafish thrombosis model for assessing antithrombotic drugs. Zebrafish 2016; 13:335.

22. McGrath P, Li CQ. Zebrafish: A predictive model for assessing drug- induced toxicity. Drug Discov Today 2008; 13:394-401.

23. Westerfield M: The Zebrafish Book: A Guide for the Laboratory Use of Zebrafish (Danio rerio). University of Oregon Eugene OR Press, Oregon, 1999.

24. Zhu JJ, Xu YQ, He JH, et al. Human cardiotoxic drugs delivered by soaking and microinjection induce cardiovascular toxicity in zebrafish. J Appl Toxicol 2013;34:139-148.

25. Zhou J, Guo SY, Zhang Y, Li CQ. Human prokinetic drugs promote gastrointestinal motility in zebrafish. Neurogastroenterol Motil 2014;26:589-595.

26. Yang R, Lao QC, Yu HP, et al. Tween- 80 and impurity induce anaphylactoid reaction in zebrafish. J Appl Toxicol 2015;35:295-301.

27. He JH, Gao JM, Huang CJ, Li CQ. Zebrafish models for assessing developmental and reproductive toxicity. Neurotoxicol Teratol 2014;42:35-42.

28. Weyand AC, Shavit JA. Zebrafish as a model system for the study of hemostasis and thrombosis. Curr Opin Hematol 2014;21:418-422.

29. Li CQ, Luo LQ, Awerman J, McGrath P: Whole zebrafish cytochrome P450 assay for assessing drug metabolism and safety. In: Zebrafish: Methods for Assessing Drug Safety and Toxicity. P. McGrath (ed), pp.103-115, Wiley-Balckwell, West Sussex, UK, 2011.

30. Li CQ, Luo LQ, McGrath P: Zebrafish xenotransplant cancer model for drug screening. In: Zebrafish: Methods for Assessing Drug Safety and Toxicity. P. McGrath (ed), pp. 219-232. Wiley-Balckwell, West Sussex, UK, 2011.

31. Williams $\mathrm{CH}$, Hong CC. Multi-step usage of in vivo models during rational drug design and discovery. Int $\mathbf{J}$ Mol Sci 2011;12:2262-2274.

32. Shimoni A, Maor-Kendler Y, Neuman Y. Verapamil-induced acute right heart failure. Am Heart J 1996;132:193-194.

33. Prisant LM. Verapamil revisited: a transition in novel drug delivery systems and outcomes. Heart Dis 2001;3:55-62.
34. Derlet RW, Horowitz BZ. Cardiotoxic drugs. Emerg Med Clin North Am 1995;13:771-791.

35. Gori M, Senni M. Sacubitril/valsartan (LCZ696) for the treatment of heart failure. Expert Rev Cardiovasc Ther 2016;14:145.

36. Testani JM, Brisco MA, Tang WHW, et al. Potential effects of digoxin on long term renal and clinical outcomes in chronic heart failure. J Cardiac Fail 2013;19:295-302.

37. Kostis JB, Vachharajani NN, Hadjilambris OW, et al. The pharmacokinetics and pharmacodynamics of irbesartan in heart failure. J Clin Pharmacol 2001;41: 935.

38. Huang J, Zhang R, Liu X, Meng Y. Impact of metoprolol treatment on cardiac function and exercise tolerance in heart failure patients with neuropsychiatric disorders. Curr Med Res Opin 2018;34:141-148.

39. Fröhlich H, Henning F, Täger T, et al. Comparative effectiveness of enalapril, lisinopril and ramipril in the treatment of patients with chronic heart failure. A propensity score matched cohort study. Eur Heart J Cardiovasc Pharmacother 2017 [Epub ahead of print]; DOI: 10.1093/ ehjcvp/pvx013.

40. Golwala H. Enalapril/carvedilol for prevention of chemotherapy-induced heart failure: an end to the problem. J Am Coll Cardiol 2013;62:2450-2451.

41. Sackner MA, Wallack AA, Bellet $S$. The diuretic effects of hydrochlorothiazide in congestive heart failure, cirrhosis, chronic renal disease and hypertension: preliminary report based on a study of 28 cases. Am J Med Sci 1959;237:575584.

42. Wei C, Jia ZH, Wu YL. Protective effects of Qiliqiangxin capsule in rabbit heart ventricle reconstitution of chronic heart failure. Chin J Difficult Complicated Cases 2007;6: 144-147.

43. Wu ZL, Xu DL, Lin S. The effects of Qiliqiangxin capsule on cardiac function and the plasma arginine vasopressin of rats with chronic heart failure. Chin J Difficult Complicated Cases 2011;10: 120-122.

44. Ma L, Yang L, Chen TD. Influence of large amount of Shenmai Injection on blood coagulation in patients with chronic heart failure. Chin J Tradit West Med (Chin) 2003; 23:275-277.

45. Wang HY, Yu BY, Yan YQ. Modulation of saponins extracted from Shenmai Powder on free calcium ion in cultured rat myocardial cells. Chin J Tradit West Med (Chin) 2002;22:848-850.

Address correspondence to: Ping Li, PhD

State Key Laboratory of Natural Medicines China Pharmaceutical University Nanjing City 210009

China

E-mail: liping2004@126.com

Chun-Qi Li, MD, PhD

Hunter Biotechnology, Inc. F1A, Building 5

No. 88 Jiangling Road

Binjiang Zone

Hangzhou City 310051

China

E-mail: jackli@zhunter.com 